CLINICAL STUDY

\title{
Surgery for adrenocortical carcinoma in The Netherlands: analysis of the national cancer registry data
}

\author{
T M A Kerkhofs, R H A Verhoeven ${ }^{1}$, H J Bonjer ${ }^{2}$, E J Nieveen van Dijkum ${ }^{3}$, M R Vriens ${ }^{4}$, J De Vries ${ }^{5}$, C H Van Eijck ${ }^{6}$, \\ B A Bonsing ${ }^{7}$, L V Van de Poll-Franse ${ }^{1,8}$, H R Haak on behalf of the Dutch Adrenal Network* \\ Department of Internal Medicine, Máxima Medical Center, Ds. Theodor Fliednerstraat 1, 5631 BM Eindhoven, Veldhoven, The Netherlands, ${ }^{1}$ Department \\ of Research, Eindhoven Cancer Registry, Comprehensive Cancer Center South, Eindhoven, The Netherlands, ${ }^{2}$ Department of Surgery, VU University \\ Medical Center, Amsterdam, The Netherlands, ${ }^{3}$ Department of Surgery, Academic Medical Center, University of Amsterdam, Amsterdam, The Netherlands, \\ ${ }^{4}$ Department of Surgery, University Medical Center Utrecht, Utrecht, The Netherlands, ${ }^{5}$ Department of Surgery, University Medical Center Groningen, \\ Groningen, The Netherlands, ${ }^{6}$ Department of Surgery, Erasmus MC, University Medical Center, Rotterdam, The Netherlands, ${ }^{7}$ Department of Surgery, \\ Leiden University Medical Center, Leiden, The Netherlands and ${ }^{8}$ Department of Medical Psychology and Neuropsychology, CoRPS - Center of Research on \\ Psychology in Somatic Diseases, Tilburg University, Tilburg, The Netherlands \\ (Correspondence should be addressed to T M A Kerkhofs; Email: t.kerkhofs@mmc.nl)
}

*(Doctors from the Dutch Adrenal Network, who collaborated in this publicaton, are listed in the Acknowledgements section)

\begin{abstract}
Objective: Adrenocortical carcinoma (ACC) is a rare disease with an estimated incidence of one to two cases per 1 million inhabitants. The Dutch Adrenal Network (DAN) was initiated with the aim to improve patient care and to stimulate scientific research on ACC. Currently, not all patients with ACC are treated in specialized DAN hospitals. The objective of the current investigation was to determine whether there are differences in survival between patients operated on in DAN hospitals and those operated on in non-DAN hospitals.

Design: The study was set up as a retrospective and population-based survival analysis.

Methods: Data on all adult ACC patients diagnosed between 1999 and 2009 were obtained from The Netherlands Cancer Registry (NCR). Overall survival was calculated and a comparison was made between DAN and non-DAN hospitals.

Results: The NCR contained data of 189 patients. The median survival of patients with European Network for the Study of Adrenal Tumors stages I-III disease was significantly longer for patients operated on in a DAN hospital $(n=46)$ than for those operated on in a non-DAN hospital $(n=37,5$-year survival 63 vs $42 \%$ ). Survival remained significantly different after correction for sex, age, year of diagnosis, and stage of disease in the multivariate analysis (hazard ratio 1.96 (95\% CI 1.01-3.81), $P=0.047$ ). Conclusion: The results associate surgery in a DAN center with a survival benefit for patients with local or locally advanced ACC. We hypothesize that a multidisciplinary approach for these patients explains the observed survival benefit. These findings should be carefully considered in view of the aim for further centralization of ACC treatment.
\end{abstract}

European Journal of Endocrinology 169 83-89

\section{Introduction}

Adrenocortical carcinoma (ACC) is a rare disease with an estimated incidence of one to two cases per 1 million inhabitants $(1,2,3)$. The prognosis is stage dependent with overall 5 -year survival ranging from $84 \%$ for stage I disease to $15 \%$ for stage IV disease $(4,5,6,7)$. Aggressive surgery is the treatment of choice, since radical resection is the only chance of cure $(7,8)$. Specialization of surgical treatment in rare conditions has been a controversial issue for many years, but increasing evidence suggests that treatment outcome is improved by centralization of care in specialized, high-volume centers $(9,10,11,12)$. There is supporting evidence that this is also the case for adrenal surgery $(13,14)$.
In The Netherlands, ACC patient care has been concentrated in the (eight) University Medical Centers for many years, due to regional patterns in the assignment of patient care and the historic role of the university hospitals as referral centers for complex pathologies. The Dutch Adrenal Network (DAN) was founded in 2004 by local specialists in the Máxima Medical Center (MMC) out of special interest and expertise in ACC. The DAN consists of the eight university hospitals and the MMC. The aim of the DAN was to formalize the existing practice of collaboration among these centers and to improve patient care, primarily for patients with ACC. The DAN stimulates (international) trial participation, facilitates research in adrenal diseases, and organizes meetings of experts, 
where research progress and clinical cases are discussed. Currently, treatment of ACC patients in The Netherlands is not performed exclusively in DAN hospitals. Whether or not a patient is directed to a DAN hospital is at the discretion of the treating physician.

Optimal treatment of ACC should be approached in a multidisciplinary way, and possible combinations of surgery, adjuvant therapy with mitotane, and cytotoxic chemotherapy for advanced stages must all be considered $(7,15,16,17,18)$. The lack of adequate expertise and/or facilities could be an argument for centralization of treatment $(4,19)$. A previous study carried out by our group demonstrated that treatment in specialized centers was beneficial to ACC patients, because improved survival was observed in patients initially operated on in DAN hospitals than in those initially treated in non-DAN hospitals (20). That study included patients treated between 1965 and 2008 $(n=175)$ and recruited patients only from DAN centers, resulting in a selected population. The absence of data on patients who were treated in general hospitals and were never directed to a DAN center was regarded as a serious limitation of that study. The objective of the current investigation was to confirm and strengthen the previous results using a population-based study design that excludes selection bias in the best possible way. The aim was to determine whether overall survival differs between ACC patients who underwent surgical treatment in a DAN hospital and those who were operated on in non-DAN hospitals.

\section{Subjects and methods}

The Netherlands Cancer Registry (NCR) is a nationwide, population-based registry, which has been collecting clinical data on cancer patients since 1989. It contains data on all patients who have histopathologically proven disease as well as most patients with cancer diagnosed otherwise. The registry also records the hospital where the patients were treated.

In The Netherlands, all hospital pathology departments participate in a nationwide network (PALGA), which supplies the NCR with lists of patients and their corresponding diagnoses. In addition, the offices of hospital medical records supply the NCR with lists of the diagnoses of outpatients and hospitalized cancer patients. Trained registrars from the NCR extract information on patient and tumor characteristics from the medical records. Topography and histology are coded according to the International Classification of Diseases for Oncology (ICD-O) (21). For this study, we selected adult patients who were diagnosed with ACC between 1st January 1999 and 31st December 2008. Pediatric patients were excluded because ACC in young children has been proposed to be a disease entity that is different from ACC in adolescents and adults. This is based on differences in presentation and survival and the strong association with $p 53$ mutations in young children but not in adults $(22,23)$. The following items were used: sex, age at the time of diagnosis, tumor laterality, disease stage, type of hospital in which surgery of the primary tumor was performed (DAN or non-DAN hospital), method of establishing diagnosis, and overall survival. Notably, the use of mitotane is not registered in the NCR. Vital statistics in the NCR are updated on a yearly basis through a link with the Municipal Personal Records Database, which contains personal files for everyone who lives or has lived in The Netherlands. In order to have at least 1 year of follow-up, the end of the observation period was 31st December 2009. The disease stage of ACC is registered in the NCR according to the 'Extent of Disease' (EoD) staging, based on clinical information and histopathological examination of the tumor (24). In order to facilitate the comparison of our data with those of other studies, the EoD staging was converted to the system proposed by the European Network for the Study of Adrenal Tumors (ENS@T) staging, which is currently accepted as the 'gold standard' in ACC research (Table 1) $(5,25)$. Because the NCR does not register tumor size for ACC, it was not possible to differentiate between ENS@T stage I and ENS@T stage II.

\section{Statistical analyses}

Between-group differences for the continuous variable 'age' were evaluated using the Kruskal-Wallis test followed by a post hoc analysis using the Mann-Whitney $U$ test with Bonferroni's adjustment $(\alpha=0.02)$. The $\chi^{2}$ test was used for comparison of the remaining categorical variables. The Kaplan-Meier estimator was used for the univariate analysis of survival data. The log-rank test was used for unadjusted comparison of survival data between DAN and non-DAN hospitals. The Cox proportional hazards regression analysis was used for the univariate and multivariate analyses for patients with ENS@T stages I-III disease. The proportional hazards assumptions were verified graphically. Stage IV patients were left out of the Cox model because clinically these patients belong to a different category.

Table 1 Staging systems in adrenocortical carcinoma: conversion from the EoD code to the ENS@T stage of disease. Sample size is indicated by $n$.

\begin{tabular}{llc}
$\begin{array}{l}\text { EoD } \\
\text { code }\end{array}$ & Explanation & $\begin{array}{c}\text { ENS@T } \\
\text { stage }(n)\end{array}$ \\
\hline 2 & Localized in the tissue of origin & I-II $(n=67)$ \\
3 & Tumor infiltration into surrounding tissue & III $(n=19)$ \\
4 & At least one positive lymph node & III $(n=7)$ \\
5 & Tumor infiltration into surrounding tissue & III $(n=1)$ \\
6 & and at least one positive lymph node & IV $(n=72)$ \\
\hline
\end{tabular}

EoD, Extent of Disease; ENS@T, European Network for the Study of Adrenal Tumors. 
Table 2 Patients' characteristics. Sample size is indicated by $n$.

\begin{tabular}{|c|c|c|c|c|c|c|}
\hline & $\begin{array}{c}\text { Total } \\
(n=189)\end{array}$ & $\begin{array}{l}\text { DAN surgery } \\
\qquad(n=70)\end{array}$ & $\begin{array}{c}\text { Non-DAN } \\
\text { surgery }(n=54)\end{array}$ & $\begin{array}{l}\text { Surgery unspec. } \\
\qquad(n=15)\end{array}$ & $\begin{array}{l}\text { No surgery } \\
\quad(n=50)\end{array}$ & $P$ value \\
\hline $\begin{array}{l}\text { Age (years; } \\
\text { median (range)) }\end{array}$ & $55(22-84)$ & $52(22-74)$ & $57(28-80)$ & $55(29-79)$ & $63(30-84)$ & $0.001^{a}$ \\
\hline \multicolumn{7}{|l|}{$\operatorname{Sex}(n(\%))$} \\
\hline Male & $78(41)$ & $26(37)$ & $25(46)$ & $6(40)$ & $21(42)$ & \multirow[t]{2}{*}{0.783} \\
\hline Female & $111(59)$ & $44(63)$ & $29(54)$ & $9(60)$ & $29(58)$ & \\
\hline \multicolumn{7}{|l|}{ Side $(n(\%))$} \\
\hline Left & $103(55)$ & $33(47)$ & $34(63)$ & $10(67)$ & $26(52)$ & \multirow[t]{4}{*}{0.381} \\
\hline Right & $84(44)$ & 37 (53) & $20(37)$ & 5 (33) & $22(44)$ & \\
\hline Bilateral & $1(1)$ & - & - & - & $1(2)$ & \\
\hline Unknown & $1(1)$ & - & - & - & $1(2)$ & \\
\hline \multicolumn{7}{|c|}{ ENS@T stage (n (\%)) } \\
\hline I-II & $67(35)$ & $35(50)$ & $26(48)$ & $6(40)$ & - & \multirow[t]{4}{*}{$<0.001$} \\
\hline III & 27 (14) & $11(16)$ & $11(20)$ & $3(20)$ & $2(4)$ & \\
\hline IV & $72(38)$ & $23(33)$ & $9(17)$ & $2(13)$ & $38(76)$ & \\
\hline Unknown & $23(12)$ & $1(1)$ & $8(15)$ & $4(27)$ & $10(20)$ & \\
\hline
\end{tabular}

DAN, Dutch Adrenal Network; Surgery unspec., patients underwent surgery, but data on the hospital involved were not available; No surgery, patients did not undergo surgery; ENS@ T, European Network for the Study of Adrenal Tumors. P value for comparison between all groups (the $\chi^{2}$ test or the Kruskal-Wallis test was used where appropriate).

${ }^{a}$ The Mann-Whitney $U$ test with Bonferroni's correction: between DAN center and non-DAN center, $P=0.009$; between DAN center and no surgery, $P<0.001$; other comparisons did not show significant results.

Only palliative treatment is possible for these patients, which means that the influence of the covariable 'surgery' is not expected to be constant in time or to be comparable to that observed in the other subgroups. Patients for whom the stage of disease was unknown were also left out of the Cox model. The results of the Cox model are reported as a hazard ratio (HR) with 95\% CI. A two-sided $P$ value $<0.05$ was considered significant. All statistical analyses were performed using SPSS 19.0 (IBM Corporation, New York, NY, USA).

\section{Results}

\section{Patients}

In this study, 189 patients who were diagnosed with ACC between 1st January 1999 and 31st December 2008 were enrolled. The diagnosis was confirmed by histological examination in 183 patients (97\%) and by cytological examination in five patients $(3 \%)$. The diagnosis was based on clinical grounds in one patient.

Median age at the time of diagnosis was 55 years (range 22-84, Table 2). Median age was significantly higher in the non-operated group than in the DAN group $(P<0.001)$ and in the non-DAN group than in the DAN group $(P=0.009)$.

There were 111 female patients (59\%). Left-sided tumors were observed in 103 patients (55\%); there was one patient with bilateral tumors. Sixty-seven patients (35\%) had stages I-II disease at the time of diagnosis. Stage III disease was confirmed in 27 patients $(14 \%)$ and stage IV disease in 72 patients (38\%). There was no information on tumor stage for 23 patients (12\%). Among all patients who underwent surgery $(n=139)$, 70 underwent primary surgery in a DAN hospital
(50\%), 54 patients were operated on in a non-DAN hospital $(39 \%)$, and 15 patients underwent surgery, but there were no data on the hospital in which the patients were operated on (11\%). Fifty patients did not undergo surgery.

\section{Survival}

Overall median survival was 19 months (95\% CI 8-29 months). Among patients with ENS@T stages I-II disease, median survival was not reached (Fig. 1). In the

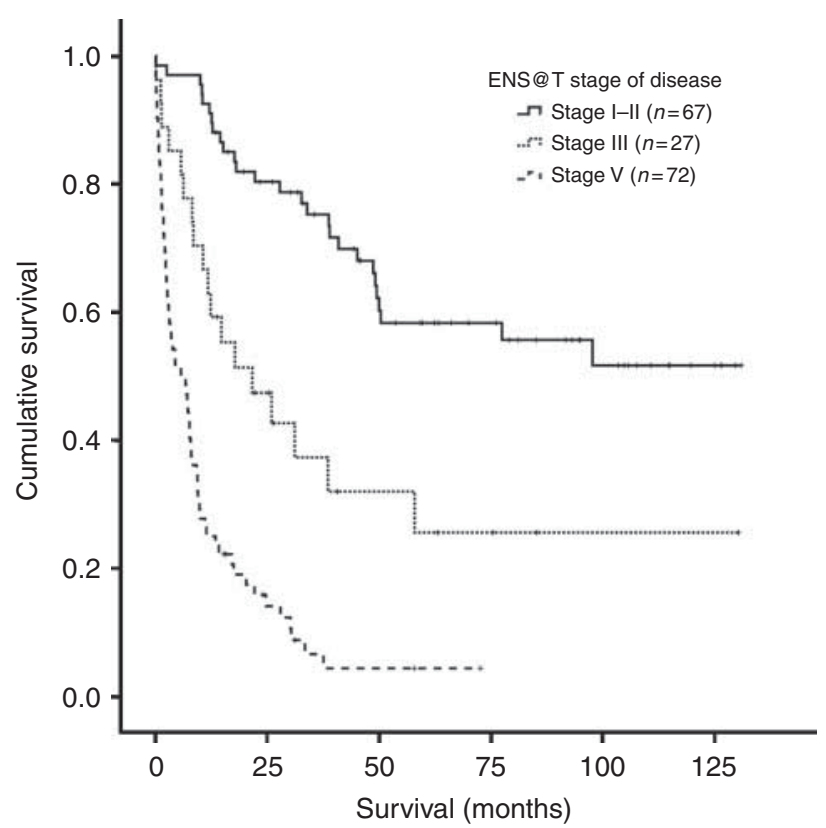

Figure 1 ENS@T, European Network for the Study of Adrenal Tumors. 
Table 3 Survival according to the location of surgery in patients with stages I-III ACC. Sample size is indicated by $n$.

\begin{tabular}{|c|c|c|c|c|c|c|}
\hline Stages I-III & $\begin{array}{c}\text { Total } \\
(n=94)\end{array}$ & $\begin{array}{l}\text { DAN surgery } \\
\quad(n=46)\end{array}$ & $\begin{array}{c}\text { Non-DAN surgery } \\
\quad(n=37)\end{array}$ & $\begin{array}{c}\text { Surgery unspec. } \\
(n=9)\end{array}$ & $\begin{array}{c}\text { No surgery } \\
(n=2)\end{array}$ & $P$ value \\
\hline $\begin{array}{l}\text { Median survival } \\
(\text { months }(95 \% \mathrm{Cl}))\end{array}$ & $58(10-106)$ & NR & $49(24-75)$ & $26(3-49)$ & - & 0.044 \\
\hline 1-year survival (\%) & 84 & 93 & 78 & 78 & - & \\
\hline 5-year survival (\%) & 49 & 63 & 42 & 22 & - & \\
\hline
\end{tabular}

DAN, Dutch Adrenal Network; Surgery unspec., patients underwent surgery, but data on the hospital involved were not available; Stage X, stage of disease unknown; NR, median survival not reached. $P$ value for comparison between DAN surgery and non-DAN surgery (log-rank test).

ENS@T stage III group, median survival was 22 months (95\% CI 5-39 months), and in the stage IV group, this was 6 months (95\% CI 2-10 months). Median survival was 19 months (95\% CI 0-55 months) in the group with unknown stage of disease (not shown in the figure).

Stages I-III Among patients with ENS@T stages I-III disease who were operated on in a DAN center $(n=46)$, median survival was not reached. After 1 year, 93\% of the patients were alive and 5-year survival was $63 \%$ (Table 3).

In the group operated on in non-DAN hospitals, median survival was 49 months $(95 \%$ CI $24-75$ months; $n=37, P=0.044$, Fig. 2). One- and 5-year survival were 78 and $42 \%$ respectively. The patients who underwent surgery, but for whom the hospital of surgery was unknown, had a median survival of 26 months (95\% CI 3-49 months), with 78 and $22 \%$ 1- and 5-year survival respectively. All patients for whom the hospital of surgery was unknown were operated on before 2004.

In the univariate Cox proportional hazards analyses, age at diagnosis, stage of disease, and surgery in a non-DAN hospital were significantly associated with the risk of death. In the multivariate analysis, these effects remained significant: surgery in a non-DAN hospital (HR $1.96(1.01-3.81), P=0.047)$, age at diagnosis (HR $1.05(1.01-1.08), P=0.005)$, and stage of disease (HR 3.08 (1.56-6.10), $P=0.001$; Table 4).

Stage IV Patients with stage IV disease who did not undergo surgery $(n=38)$ had a median survival of 2 months (95\% CI 1-3 months, Table 5). In comparison, patients who did undergo surgery regardless of the type of hospital $(n=34)$ had a median survival of 10 months (95\% CI $4-16$ months, $P<0.001)$. There was no significant difference in survival between patients with ENS@T stage IV disease operated on in a DAN hospital and those operated on in a non-DAN hospital (median survival 9 vs 20 months, $P=0.955$, not given in the table).

\section{Discussion}

The results of our population-based study confirm that surgical removal of the primary tumor in a DAN hospital is associated with a survival benefit compared with primary surgery in a non-DAN hospital for patients with local or locally advanced ACC.

Our previous study showed a survival benefit for patients who were operated on in DAN centers compared with those operated on in non-DAN centers, similar to the one observed in the present study in stages I-III patients (20). The prior study contained only data of patients who had been treated in a DAN center at any time during the course of their disease. This design resulted in a selected population because patients who were treated and followed up in non-DAN hospitals were missing. The present study is based on the independent NCR and includes patients diagnosed between 1999 and 2009. This results in a population that approaches as close as possible the true number of all ACC patients in The Netherlands. Compared with the prior study, an additional 98 patients from 1999 to 2008 were included, from which 30 were operated on in a non-DAN center, 16 in a DAN center, and 15 in an unspecified hospital. Thirty-seven patients did not undergo surgery.

A German study has suggested that patients who were initially treated in a specialized center had a better

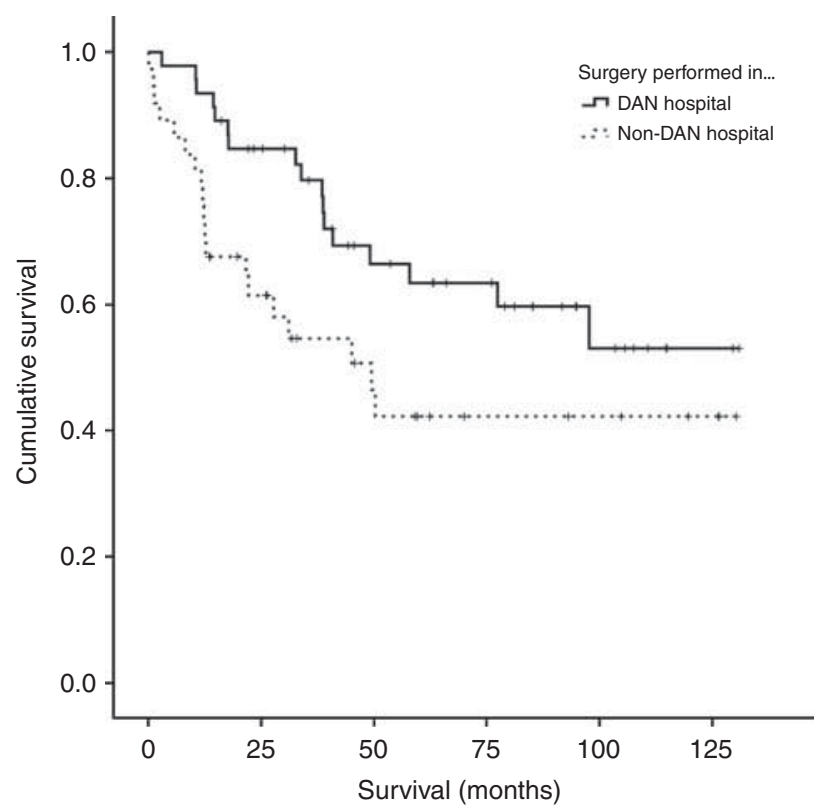

Figure 2 DAN, Dutch Adrenal Network. 
Table 4 Univariate and multivariate analyses of overall survival of 92 surgically treated patients with stages I-III ACC.

\begin{tabular}{|c|c|c|c|c|}
\hline \multirow[b]{2}{*}{ Variable } & \multicolumn{2}{|c|}{ Univariate analysis } & \multicolumn{2}{|c|}{ Multivariate analysis } \\
\hline & $\mathrm{HR}$ & $P$ value & $\mathrm{HR}$ & $P$ value \\
\hline \multicolumn{5}{|l|}{ Sex } \\
\hline Female $(n=56)$ & 1 & & 1 & \\
\hline Male $(n=36)$ & $0.93(0.50-1.74)$ & 0.815 & $0.80(0.42-1.51)$ & 0.489 \\
\hline Age & $1.04(1.02-1.07)$ & 0.002 & $1.05(1.01-1.08)$ & 0.005 \\
\hline Year of diagnosis & $1.08(0.96-1.21)$ & 0.180 & $0.97(0.84-1.12)$ & 0.656 \\
\hline \multicolumn{5}{|l|}{ ENS@T stage } \\
\hline Stages I-II $(n=67)$ & 1 & & 1 & \\
\hline Stage III $(n=25)$ & $2.68(1.43-5.03)$ & 0.002 & $3.08(1.56-6.10)$ & 0.001 \\
\hline \multicolumn{5}{|l|}{ Surgery in a DAN hospital } \\
\hline Yes $(n=46)$ & 1 & & 1 & \\
\hline Unknown $(n=9)$ & $2.79(1.16-6.75)$ & 0.023 & $1.80(0.69-4.65)$ & 0.227 \\
\hline No $(n=37)$ & $1.94(1.01-3.75)$ & 0.047 & $1.96(1.01-3.81)$ & 0.047 \\
\hline
\end{tabular}

ENS@T, European Network for the Study of Adrenal Tumors; DAN, Dutch Adrenal Network; HR, hazard ratio for mortality. $P$ value for the Cox regression analysis (univariate and multivariate as indicated).

outcome than those initially treated in a general hospital (4). However, statistical power was limited, and a survival benefit was only demonstrated for stage II patients. Arguments in favor of centralization were that patients would benefit from the more frequent use of adjuvant therapy, expertise of experienced physicians, and a more individually tailored follow-up. Another recent series has reported superior disease-free survival for a group of 28 patients who underwent primary surgery in a specialized center compared with 190 patients who were transferred to that institution after treatment in other hospitals (26). Similar to the previous Dutch study, these studies are compromised by selection and referral bias, because all patients were included solely from specialized centers. In such a design, the number of patients curatively treated in other hospitals without recurrent or metastatic disease remains unknown. The strength of the current study design is that selection bias is virtually ruled out, as all confirmed cases of ACC are included. Notably, the total number of 189 patients matches with an expected incidence of one to two cases per million for a population of about 16 million inhabitants during a 10-year period.

The population-based setup also has a drawback: it does not facilitate the determination of the underlying cause for the survival benefit because the cancer registry does not hold many details about individual patients. We speculate that the explanation lies beyond a mere increase in surgical volume. In a DAN hospital, ACC patients are discussed preoperatively in a multidisciplinary team including an endocrinologist, surgeon, oncologist, radiotherapist, and radiologist. Adjuvant treatment is carried out according to up-to-date guidelines and most DAN centers offer the possibility of participation in international trials regarding ACC (27). All aspects of treatment, from disease staging to follow-up visits, benefit from a multidisciplinary approach taken by physicians who are experienced in treating patients with ACC. If it is assumed that patients who are operated on in a DAN hospital have received additional treatment and follow-up there as well, the observed survival benefit for primary surgery in a DAN center can be extrapolated to 'treatment in DAN'. Whether or not patients who are operated on in non-DAN hospitals received additional treatment later in the course of their disease would not change the interpretation of the present results.

The concept that rare diseases should be treated in a limited number of specialized hospitals is intuitively logical and is increasingly instituted in health care systems. In The Netherlands, a centralized approach has been introduced for other rare diseases such as esophageal/gastric cardia cancer and pancreatic cancer and has proven to be effective $(28,29,30)$. In highvolume oncological diseases such as breast or colon cancer, centralization of care is a big issue as well. The effects of introducing minimum volume requirements for oncological surgery have recently been investigated in The Netherlands. Interestingly, this report shows that low-volume centers do not necessarily perform worse than high-volume centers. This suggests that besides surgical volume other factors are responsible, which is in agreement with our hypothesis regarding the treatment of ACC in DAN centers (31).

Table 5 Survival in patients with stage IV ACC with and without surgical treatment. Sample size is indicated by $n$.

\begin{tabular}{lcccc}
\hline Stage IV & $\begin{array}{c}\text { Total } \\
(n=72)\end{array}$ & $\begin{array}{c}\text { Surgery } \\
(n=34)\end{array}$ & $\begin{array}{c}\text { No surgery } \\
(n=38)\end{array}$ & $\boldsymbol{P}$ value \\
\hline $\begin{array}{c}\text { Median survival } \\
\text { (months (95\% Cl)) }\end{array}$ & $6(2-10)$ & $10(4-16)$ & $2(1-3)$ & $<0.001$ \\
1-year survival (\%) & 25 & 47 & 5 & \\
5-year survival (\%) & 4 & 9 & 0 & \\
\hline
\end{tabular}

$P$ value for comparison between surgery and no surgery (log-rank test). 
The survival benefit in stage IV patients who underwent surgery vs those who did not has been observed before (20). Because this observation is probably in part attributable to selection bias, these data have to be interpreted with caution. Based on theoretical reasoning, a radical resection might be beneficial in stage IV patients. Debulking surgery might alleviate symptoms and yield a survival benefit in patients with slowly progressive disease. Surgery of stage IV patients is mainly performed in specialized centers. In contrast to the stages I-III group, no significant difference in survival was observed between DAN and non-DAN hospitals for stage IV patients.

The present study has limitations. As has been mentioned earlier, detailed information on individual treatments or course of disease was not available, which means that it was not possible to confirm the cause of the observed survival benefit or to compare disease-free survival between the two groups. Also, the lack of a central pathology review makes the NCR dependent on the accurate registration of the true diagnosis by the local pathologist and physician. Finally, referral bias cannot be excluded.

The present population-based study associates surgical removal of primary local or locally advanced ACC in a DAN center with a survival benefit compared with patients treated in a non-DAN hospital. The study design does not permit the determination of the cause of the difference. However, the authors believe that these findings underscore the need for further centralization of ACC treatment. Initiatives have been undertaken to raise awareness of the disease and the DAN and to intensify collaboration between the DAN and the ENS@T.

\section{Declaration of interest}

The authors declare that there is no conflict of interest that could be perceived as prejudicing the impartiality of the research reported.

\section{Funding}

This research did not receive any specific grant from any funding agency in the public, commercial or not-for-profit sector.

\section{Author contribution statement}

T M A Kerkhofs and R H A Verhoeven were involved in data collection. T M A Kerkhofs planned and performed the analyses and wrote the paper. R H A Verhoeven checked the statistical analyses. L V Van de Poll-Franse and H R Haak supervised and commented on the analyses. All authors contributed to data interpretation, reviewed the draft, and approved the final version of this paper.

\section{Acknowledgements}

The authors thank the members of the Dutch Adrenal Network who collaborated in this study: E M Eekhoff, PhD (Department of Endocrinology, VU University Medical Center, Amsterdam, The Netherlands), I G C Hermsen, PhD (Department of Internal Medicine, Máxima Medical Center, Eindhoven, Veldhoven, The Netherlands),
H J Timmers, PhD (Department of Endocrinology, Radboud University Medical Center, Nijmegen, The Netherlands), B Havekes, PhD (Department of Endocrinology, Maastricht University Medical Center, Maastricht, The Netherlands), and G Den Butter, PhD (Department of Surgery, Máxima Medical Center, Eindhoven, Veldhoven, The Netherlands). Presented in part at the European Congress of Endocrinology 2012 (Florence, Italy) and at the Dutch Congress of Surgery 2012 (Veldhoven, The Netherlands).

\section{References}

1 Libe R, Fratticci A \& Bertherat J. Adrenocortical cancer: pathophysiology and clinical management. Endocrine-Related Cancer 2007 14 13-28. (doi:10.1677/erc.1.01130)

2 Allolio B \& Fassnacht M. Clinical review: adrenocortical carcinoma: clinical update. Journal of Clinical Endocrinology and Metabolism 200691 2027-2037. (doi:10.1210/jc.2005-2639)

3 Kebebew E, Reiff E, Duh QY, Clark OH \& McMillan A. Extent of Disease at presentation and outcome for adrenocortical carcinoma: have we made progress? World Journal of Surgery 200630 872-878. (doi:10.1007/s00268-005-0329-x)

4 Fassnacht M, Johanssen S, Fenske W. Weismann D, Agha A, Beuschlein F, Fuhrer D, Jurowich C, Quinkler M, Petersenn S et al. Improved survival in patients with stage II adrenocortical carcinoma followed up prospectively by specialized centers. Journal of Clinical Endocrinology and Metabolism $2010 \quad 95$ 4925-4932. (doi:10.1210/jc.2010-0803)

5 Fassnacht M, Johanssen S, Quinkler M, Bucsky P, Willenberg HS, Beuschlein F, Terzolo M, Mueller HH, Hahner S \& Allolio B. Limited prognostic value of the 2004 International Union Against Cancer staging classification for adrenocortical carcinoma: proposal for a revised TNM classification. Cancer 2009115 243-250. (doi:10.1002/cncr.24030)

6 Malandrino P, Al Ghuzlan A, Castaing M, Young J, Caillou B, Travagli JP, Elias D, de Baere T, Dromain C, Paci A et al. Prognostic markers of survival after combined mitotane- and platinum-based chemotherapy in metastatic adrenocortical carcinoma. EndocrineRelated Cancer 201017 797-807. (doi:10.1677/ERC-09-0341)

7 Fassnacht M \& Allolio B. Clinical management of adrenocortical carcinoma. Best Practice \& Research. Clinical Endocrinology \& Metabolism 200923 273-289. (doi:10.1016/j.beem.2008.10.008)

8 Schteingart DE, Doherty GM, Gauger PG, Giordano TJ, Hammer GD, Korobkin M \& Worden FP. Management of patients with adrenal cancer: recommendations of an International Consensus Conference. Endocrine-Related Cancer 200512 667-680. (doi:10.1677/ erc.1.01029)

9 Gooiker GA, van Gijn W, Wouters MW, Post PN, van de Velde CJ, Tollenaar RA \& Signalling Committee Cancer of the Dutch Cancer Society. Systematic review and meta-analysis of the volume-outcome relationship in pancreatic surgery. British Journal of Surgery 201198 485-494. (doi:10.1002/bjs.7413)

10 Wouters MW, Gooiker GA, van Sandick JW \& Tollenaar RA. The volume-outcome relation in the surgical treatment of esophageal cancer: a systematic review and meta-analysis. Cancer 2012118 1754-1763. (doi:10.1002/cncr.26383)

11 Bilimoria KY, Phillips JD, Rock CE, Hayman A, Prystowsky JB \& Bentrem DJ. Effect of surgeon training, specialization, and experience on outcomes for cancer surgery: a systematic review of the literature. Annals of Surgical Oncology 2009 16 1799-1808. (doi:10.1245/s10434-009-0467-8)

12 Chowdhury MM, Dagash H \& Pierro A. A systematic review of the impact of volume of surgery and specialization on patient outcome. British Journal of Surgery 200794 145-161. (doi:10. 1002/bjs.5714)

13 Villar JM, Moreno P, Ortega J, Bollo E, Ramirez CP, Munoz N, Martinez C, Dominguez-Adame E, Sancho J, del Pino JM et al. Results of adrenal surgery. Data of a Spanish National Survey. Langenbeck's Archives of Surgery 2010395 837-843. (doi:10.1007/ s00423-010-0697-z) 
14 Park HS, Roman SA \& Sosa JA. Outcomes from 3144 adrenalectomies in the United States: which matters more, surgeon volume or specialty? Archives of Surgery $2009 \mathbf{1 4 4}$ 1060-1067. (doi:10.1001/archsurg.2009.191)

15 Terzolo M, Angeli A, Fassnacht M, Daffara F, Tauchmanova L, Conton PA, Rossetto R, Buci L, Sperone P, Grossrubatscher E et al. Adjuvant mitotane treatment for adrenocortical carcinoma. New England Journal of Medicine 2007356 2372-2380. (doi:10.1056/ NEJMoa063360)

16 Berruti A, Fassnacht M, Baudin E, Hammer G, Haak H, Leboulleux S, Skogseid B, Allolio B \& Terzolo M. Adjuvant therapy in patients with adrenocortical carcinoma: a position of an international panel. Journal of Clinical Oncology 201028 e401-e402 (author reply e403). (doi:10.1200/JCO.2009.27.5958)

17 Fassnacht M, Libe R, Kroiss M \& Allolio B. Adrenocortical carcinoma: a clinician's update. Nature Reviews. Endocrinology 20117 323-335. (doi:10.1038/nrendo.2010.235)

18 Tacon LJ, Prichard RS, Soon PS, Robinson BG, Clifton-Bligh RJ \& Sidhu SB. Current and emerging therapies for advanced adrenocortical carcinoma. Oncologist $2011 \quad 16$ 36-48. (doi:10.1634/ theoncologist.2010-0270)

19 Johanssen S, Hahner S, Saeger W, Quinkler M, Beuschlein F, Dralle H, Haaf M, Kroiss M, Jurowich C, Langer $\mathrm{P}$ et al. Deficits in the management of patients with adrenocortical carcinoma in Germany. Deutsches Ärzteblatt International 2010 $107885-891$.

20 Hermsen IG, Kerkhofs TM, Butter G, Kievit J, van Eijck CH, Nieveen van Dijkum EJ, Haak HR \& Dutch Adrenal Network . Surgery in adrenocortical carcinoma: importance of national cooperation and centralized surgery. Surgery 2012152 50-56. (doi:10.1016/j.surg.2012.02.005)

21 Fritz AG. International Classification of Diseases for Oncology: ICD-O, 3rd edn, pp 240. Geneva: World Health Organization, 2000.

22 Dehner LP \& Hill DA. Adrenal cortical neoplasms in children: why so many carcinomas and yet so many survivors? Pediatric and Developmental Pathology 200912 284-291. (doi:10.2350/0806-0489.1)

23 Faria AM \& Almeida MQ. Differences in the molecular mechanisms of adrenocortical tumorigenesis between children and adults. Molecular and Cellular Endocrinology $201235152-57$. (doi:10.1016/j.mce.2011.09.040)
24 Guinee VF. The International Cancer Patient Data Exchange System (ICPDES). Health Reports/Statistics Canada 19935 97-103.

25 Lughezzani G, Sun M, Perrotte P, Jeldres C, Alasker A, Isbarn H, Budaus L, Shariat SF, Guazzoni G, Montorsi F et al. The European Network for the Study of Adrenal Tumors staging system is prognostically superior to the International Union against cancerstaging system: a North American validation. European Journal of Cancer 201046 713-719. (doi:10.1016/j.ejca.2009.12.007)

26 Grubbs EG, Callender GG, Xing Y, Perrier ND, Evans DB, Phan AT \& Lee JE. Recurrence of adrenal cortical carcinoma following resection: surgery alone can achieve results equal to surgery plus mitotane. Annals of Surgical Oncology 201017 263-270. (doi:10.1245/s10434-009-0716-x)

27 Berruti A, Baudin E, Gelderblom H, Haak HR, Porpiglia F, Fassnacht M, Pentheroudakis G \& on behalf of the ESMO Guidelines Working Group. Adrenal cancer: ESMO Clinical Practice Guidelines for diagnosis, treatment and follow-up. Annals of Oncology 201223 vii131-vii138. (doi:10.1093/annonc/mds231)

28 van de Poll-Franse LV, Lemmens VE, Roukema JA, Coebergh JW \& Nieuwenhuijzen GA. Impact of concentration of oesophageal and gastric cardia cancer surgery on long-term populationbased survival. British Journal of Surgery 201198 956-963. (doi:10.1002/bjs.7493)

29 Lemmens VE, Bosscha K, van der Schelling G, Brenninkmeijer S, Coebergh JW \& de Hingh IH. Improving outcome for patients with pancreatic cancer through centralization. British Journal of Surgery 201198 1455-1462. (doi:10.1002/bjs.7581)

30 de Wilde RF, Besselink MG, van der Tweel I, de Hingh IH, van Eijck CH, Dejong CH, Porte RJ, Gouma DJ, Busch OR, Molenaar IQ et al. Impact of nationwide centralization of pancreaticoduodenectomy on hospital mortality. British Journal of Surgery 2012 99 404-410. (doi:10.1002/bjs.8664)

31 Ho V, de Raaf A, van der Hoeven K \& Jansen-Landheer M. IKNL berekent effect volumenormen op ziekenhuizen en patiënten. Medisch Contact 2013 issue 1 34-37.

Received 18 February 2013

Revised version received 19 April 2013

Accepted 2 May 2013 